\title{
The “Too-Much-of-a-Good-Thing” Effect of Job Autonomy and Its Explanation Mechanism
}

\author{
Enxi Zhou \\ School of Management, Jinan University, Guangzhou, China \\ Email: 18819479232@163.com
}

How to cite this paper: Zhou, E. X. (2020). The "Too-Much-of-a-Good-Thing" Effect of Job Autonomy and Its Explanation Mechanism. Psychology, 11, 299-313. https://doi.org/10.4236/psych.2020.112019

Received: December 31, 2019

Accepted: February 10, 2020

Published: February 13, 2020

Copyright () 2020 by author(s) and Scientific Research Publishing Inc. This work is licensed under the Creative Commons Attribution International License (CC BY 4.0).

http://creativecommons.org/licenses/by/4.0/

\begin{abstract}
The "Taylorian" management thinking of the outside control in the past has been unable to adapt to the current Internet era. The external control has changed to the flexible management of self-control, and the increase of job autonomy has become a trend. Job autonomy refers to the discretion of an organization to allow employees to complete tasks when, where, in what order and in what manner. In the past, the mainstream theoretical models and empirical studies have found that the job autonomy has a positive impact on employees. But currently the new research has found that the excessive job autonomy can have a negative impact on employees, and there is a "too-much-of-a-good-thing" effect. This article mainly expounds the "too-much-of-a-good-thing" effect of the job autonomy, and then, explains the effect by the two types mechanisms, "additive benefit and cost" and "interactive motivation and opportunity". Finally, this article puts forward some issues that should be paid attention to future researches.
\end{abstract}

\section{Keywords}

Job Autonomy, Too-Much-of-a-Good-Thing, Interactive Motivation and Opportunity, Additive Benefit and Cost

\section{Introduction}

Under the traditional "Taylor-style" management model, employees' work is often constrained by the organization. Limited job autonomy has become an important reason for reducing employee enthusiasm and hindering creativity. In the fast changing Internet era, the management methods of controlling employees seem to be outdated, and they have turned to more flexible management methods. Organizations are increasingly implementing job autonomy policies to improve employee motivation and creativity. Several surveys show the general 
increase in job autonomy: According to a survey by the British Federation of Industries (CBI), $13 \%$ of UK employers offered telecommuting in 2006, and in 2011 this rate rose to 59\%. Similarly, a survey from the Ministry of International Affairs and Communications revealed that the proportion of Japanese companies using remote offices increased from $11.4 \%$ in 2014 to $16.2 \%$ in 2015 . Obviously, job autonomy is showing a straight upward trend. However, the job autonomy does not always have a positive impact. In a highly flexible and indirectly controlled work environment, too much of job autonomy may bring uncertainty and ambiguity, which will have the opposite effect and produce "too-much-of-a-good-thing" effect.

Previous research has shown that job autonomy is an important job characteristic and can have many positive consequences. From the perspective of the work resource-requirement model, on the one hand job autonomy can increase positive work resources, and on the other hand job autonomy can buffer the negative effects of work requirements. In general, previous theoretical models and empirical studies have found that job autonomy is a positive work resource and can have a positive impact on employees. However, recent studies have found that job autonomy does not always have a positive effect, and excessive job autonomy can also have negative effects. For example, excessive job autonomy can reduce employee happiness, and scholars have confirmed this view through empirical research (Baltes et al., 2002; Taris, 2006). In addition, excessive job autonomy will aggravate employees' job burnout, and cause unethical behavior of employees (Lu et al., 2017). These studies show that increasing autonomy brings positive effects, and excessive job autonomy can also have negative effects. These contradictions have attracted scholars' attention.

This article focuses on this contradiction, summarizes and combs the literature on job autonomy, proposes the "too-much-of-a-good-thing" effect of job autonomy, and aims to explain why and when this effect occurs. Specifically, there is a critical point for the positive role of job autonomy. When the critical point is reached, the positive relationship between the antecedent variable and the ideal result variable stops, and when the critical point is exceeded, the unexpected result will be produced, thus the overall non-linear relationship is inverted U-shaped. After the literature review, we find that the "too-much-of-a-good-thing" effect of job autonomy not only affects employees' work attitude, but also their work behavior. To this end, this article first summarizes the impact of job autonomy's "too-much-of-a-good-thing" effect, and then, based on the dynamic mechanism, innovatively uses the "additive benefit and cost" and "interactive motivation and opportunity" to explain the effects. Finally, I explore future directions worthy of attention and research.

\section{The Concept of Job Autonomy}

Job autonomy first appeared in the job characteristic model, which was defined by Hackman and Oldham (1976) as "Organizations provide individuals with the 
ability to schedule work and determine the degree of freedom, independence, and self-determination of work procedures". This definition includes both autonomy and independence, confusing two different characteristics. In order to define job autonomy more accurately and specifically, Breaugh (1985) proposed that job autonomy refers to "the degree to which employees can control and decide on their own methods of work, work arrangements, and work standards". Similarly, Morgeson and Humphrey (2006) summarized job autonomy as "the degree to which an organization allows employees to freely, independently, and autonomously make work arrangements, work decisions, and work methods". From the development of the definition of job autonomy, previous scholars have studied job autonomy at the level of work tasks. However, with recent developments in research, such as flexible working hours and changing workplaces, job autonomy has been extended to a wider range of work levels (Kubicek, Paškvan, \& Bunner, 2017). In combination with the new work form of the current Internet of everything, Kubicek et al. (2017) combined these different aspects and believed that job autonomy refers to the discretion of employees to complete tasks when, where, in what order and in what way. It is worth mentioning that job autonomy is the organization's autonomy to give employees the freedom to work. It is different from individual autonomy. Individual autonomy emphasizes that individuals are free to choose to engage in an action based on their own interests or personal beliefs.

\section{The "Too-Much-of-a-Good-Thing" Effect of Job Autonomy}

\subsection{Positive Effects of Job Autonomy}

Job autonomy first appeared in the evolution of job characteristic model (Hackman \& Oldham, 1976), and scholars made in-depth explorations of job autonomy. As a job characteristic, job autonomy can have a huge impact on individuals and organizations. It promotes the appearance of positive results by changing the individual's psychological state (responsibility), including improving internal job motivation, job satisfaction, job performance, and reducing absenteeism and turnover. Later, in the job requirement-resource model (Bakker \& Demorouti, 2007), it is also used as a job resource to alleviate the negative impact of job requirements on individuals. Scholars have done a lot of research to prove the positive effects of job autonomy, which can be divided into psychological level and behavioral level.

The positive impact of job autonomy on the psychological level of employees is mainly divided into two aspects. On the one hand, it is conducive to improving employees' mental health and job satisfaction; on the other hand, it can reduce employee burnout and reduce intentions to leave. Park and Jang (2015) stratified sampling from various regions in the United States, with a sample size of 2254, covering almost all industries. The study found that job autonomy has a positive impact on employee mental health. Searcy (2012) found through a large sample survey (12,836 employees in the UK) that job autonomy has a significant 
positive impact on happiness and job satisfaction. Cynthia (2005) analyzed the data of the National Labor Force Change Study in 2002, and conducted a large sample survey of 3504 workers. Job autonomy has a positive impact on employee life satisfaction and family satisfaction through a sense of control. Kimmsw \& Stoner (2008) surveyed 346 social workers in California and found that job autonomy can alleviate the negative impact of role stress on burnout, and also found that autonomy can reduce employee turnover intention.

The positive effects of job autonomy are also reflected in the behavioral level of employees, which are mainly reflected in the improvement of creativity, increase of work input, good work performance, and the emergence of organizational citizenship behavior. Sia and Appu (2015) have a positive impact on workplace creativity through the 304 IT technical employees of different companies, job autonomy and its three dimensions. They believe that autonomy allows employees to experiment with different ways and methods of work. It enables them to find ideas and apply them by developing them on a small scale. Malinowska et al. (2018) believe that giving autonomy to work promotes internal motivation for employees to work, which in turn will increase employees' work commitment. Morgeson \& Humphrey (2006) showed that when workers "autonomy is low, workers" performance may decrease due to monotonous work or lack of skills. However, when they experience the fit between their autonomy and the task environment, individuals perform better. Employees who gain more autonomy at work are more likely to participate in organizational citizenship (Morgeson \& Humphrey, 2006; Yang et al., 2017). Increasing job autonomy Employees provide greater discretion, allowing them to better fulfill their responsibilities, and allowing employees to have a broader definition of roles.

\subsection{Negative Effects of Excessive Job Autonomy}

From the above point of view, the increase of job autonomy seems to play a positive role in individual work. However, recent studies have found that job autonomy is not a kind of resource that can always have a positive impact, excessive job autonomy will have a negative impact on employees and organizations, that is to say, "too-much-of-a-good-thing" effect.

\subsubsection{Reducing Job Happiness and Satisfaction}

For the study of the relationship between job autonomy and work well-being, there are inconsistent results. Most of the previous studies think that there is a positive relationship between them, and later gradually some studies found that they are not always positive linear relationship. The vitamin model proposed by Warr (1994) challenges the hypothesis that job autonomy is usually beneficial. He believes that the relationship between job autonomy and happiness is inverted U-shaped. When the job autonomy is too high, the happiness of employees will be reduced. Because high job autonomy may no longer mean "beauty", but become a "necessity" of work. Employees must arrange their work properly, which instead becomes a passive pressure. Warr (1994) supported the 
proposition of vitamin model through sample survey. He found that there was a nonlinear relationship between job autonomy and employee happiness. However, this relationship is similar to the inverted U-shaped curve. With the improvement of job autonomy, the curve extends downward. In the higher level of autonomy, employee well-being shows a downward trend. About job satisfaction, Baltes et al. (2002) also verified that job autonomy and job satisfaction follow the inverted U curve. He conducted a survey of 501 full-time employees from manufacturing and accounting firms in the Midwest of the United States and recruited employees from various industries on the Internet. The sample was representative. The results show that when the level of job autonomy increases from low to medium, the job satisfaction will increase, but in the high level of job autonomy, the job satisfaction will decrease.

\subsubsection{Reducing Work Efficiency}

In individual work, the most direct negative effect of excessive job autonomy is the reduction of work efficiency. On the one hand, excessive job autonomy leads to an increase in the time to complete tasks. In the Internet environment, employees can choose various network tools to work independently, such as email, internal communication software, wechat, etc. But, in the process of using electronic software to work, the main tasks are usually interfered by other online information. Once interrupted, its work efficiency will decline, and employees need more time to recover to the main task. In addition, Kelliher and Anderson (2010) found in a study that compared with employees with fixed working hours, employees with higher job autonomy use longer working hours to strengthen their work style and complete their work. On the other hand, excessive job autonomy will reduce the dependence on colleagues, resulting in the inefficiency of some tasks that need cooperation. In the meta analysis of the impact of work time autonomy on work results, Baltes et al. (1999) also found that highly flexible work time reduced work efficiency compared with less flexible work time. They believe that a high level of flexibility can be inconvenient, not beneficial, for employees who are highly dependent on their colleagues to complete their tasks. For example, employees may experience the negative impact of flexible working hours because they cannot communicate or cooperate with other employees because they do not work at the same time.

\subsubsection{Leading to Counterproductive Behavior}

Excessive job autonomy may trigger counterproductive behavior by employees. Excessive increase of job autonomy may also reduce external supervision and other controls, which are used to reduce anti production behavior (Brink et al., 2016). Counterproductive behavior refers to the voluntary behavior of organization members that violates important organizational norms and threatens the well-being of the organization or its members (Robinson \& Bennett, 1995). There are many forms of counterproductive behavior, such as fraud, theft, falsification of documents and abuse of company time or assets. Vardi and Weitz 
(2004) point out that excessive job autonomy leaves room for individual behavioral performance at work, which actually creates opportunities for behavioral deviations. In addition, ACFE research in 2010 showed that a significant portion of organizational fraud and theft occurs at the highest levels of the company, which may be partly attributed to the increased opportunities and job autonomy provided by these positions. There are two main types of situations that cause counterproductive behavior-triggers and opportunities. Triggering events may take the form of financial or social pressure, unfair treatment, poor working conditions; Opportunity is the perception of the situation in which counterproductive behavior can occur. Perception of job autonomy will be regarded as an opportunity to increase counterproductive behavior. In a more autonomous environment, the frequency of the behavior will increase. In order to better explain excessive autonomy can increase the counterproductive behavior, Brink (2016) survey of 253 Chinese employees engaged in accounting work, including the private sector accounting (215 people), the listed company (20 respondents), public accounting firms (eight respondents) and government enterprises (6 people), the study measured the job autonomy, the counterproductive behavior of respondents. The measured include occupying company property without permission, resting without permission during working hours, being late for work without permission. Data analysis shows that job autonomy has a positive impact on counterproductive behavior, and high job autonomy will lead counterproductive behavior.

\subsubsection{Leading to Unethical Behavior}

Excessive job autonomy can lead to unethical behavior by employees. According to the self-determination theory, when individuals gain autonomy in their work, they will experience free will. But it is important that free will not only generate positive attitudes and behaviors, but may also induce individuals to feel that actions that are not subject to rules are in the form of "self-interest", such as laziness during work hours and abuse of organizational resources. In fact, recent studies have shown that feelings that are not subject to rules are positively related to immoral tendencies in individual behavior (Gino \& Wiltermuth, 2014), so experiencing a high level of job autonomy can be induced by people being free from rules to increase unethical behavior. Lu et al. (2017) confirmed this view through surveys and experiments. The paper questionnaire measured the job autonomy and unethical behavior of 390 Israeli employees. The results show that job autonomy promotes employees' unethical behavior. To further verify the conclusions, experimental measurements were performed. The sample was 410 employees from Amazon, which were randomly divided into high, medium, and low autonomy groups and control groups. Reward based on the correct amount, false reporting rate proves unethical behavior; finally, use the questionnaire to measure the job autonomy of the participants. The results showed that the cheating rate in the high job autonomy group was as high as $18.9 \%$, which was significantly higher than the other three groups. The difference in cheating 
rates in the control group (8.3\%), low autonomy (8.6\%), and medium autonomy (10.8\%) was not significant.

Through combing analysis, it can be found that a modest increase in job autonomy will promote individual work performance and have a beneficial impact on the organization. However, excessive job autonomy will have the effect of "being too late", which is contrary to the original intention of promoting job autonomy. But why is there such a "too-much-of-a-good-thing" effect? From the perspective of dynamic mechanism, this article uses the "additive benefit and cost" and "interactive motivation and opportunity" to explain.

\section{Explanation Mechanism of the "Too-Much-of-a-Good-Thing" Effect}

In the past, most studies have divided "over" and "less than" into two intervals during which the independent variable acts on the dependent variable. The effect is explained from why it rises before the critical point and how it decreases after the critical point. Crawford and Lepine (2013) believe that

"too-much-of-a-good-thing" is because the independent variables include an independent or interconnected adversarial relationship. The combination shows the "net effect" in the independent and dependent variables. In the relationship, an inverted U-shaped non-linear is presented. By examining the two opposite effects, and how they are tuned in the course of action, it can help researchers understand why the outcome variable increases or decreases. Xing Lu et al. (2018) distinguished the causes of the "too-much-of-a-good-thing" effect according to the interaction of potential mechanisms as "additive benefit and cost" and "interactive motivation and opportunity". This article will use this mechanism to analyze how job autonomy has the effect.

\subsection{Additive Benefit and Cost}

In the "too-much-of-a-good-thing" effect, gains and losses show dynamic changes with the growth of independent variables. Among them, the benefit refers to the increase of the dependent variable due to the change of the independent variable; Loss refers to a reduction in the dependent variable due to a change in the independent variable. The key reason for "too-much-of-a-good-thing" is that the income brought by the level change of independent variables cannot balance the corresponding loss, which is commonly known as "the loss is not worth the gain".

Specifically, each specific independent variable level corresponds to a marginal return and a marginal loss respectively, and the marginal net return of the dependent variable is equal to the difference between the marginal return and the marginal loss. In the first case, as the independent variable increases, the marginal gain increases and the marginal loss increases, but the growth rate of the latter is greater than the former. In the second case, as the independent variable increases, the marginal returns diminish, and the marginal losses increase. Then, 
in the first half of the inverted U-shape, the marginal gain is greater than the marginal loss, and the marginal net income is positive, showing a positive impact. The reversal threshold occurs when the marginal gain is equal to the marginal loss, and the marginal growth rate is zero, corresponding to the critical point of the inverted $U$-shaped curve, which means that the best effect has been achieved. In the second half of the inverted $U$-shape, the growth rate of marginal loss exceeds the growth rate of marginal income, and the marginal net income is negative, after which it has a negative impact.

The first case of the additive benefit and cost can explain the "too-much-of-a -good-thing" effect of job autonomy on subjective happiness an work efficiency (Figure 1). The increase of job autonomy will generate two paths of gain and loss of subjective well-being and work efficiency. This article will explain these two paths from the perspective of limited resources and their superimposed effect.

Regarding the gain path, from the job requirement-resource model (Bakker \& Demorouti, 2007), job autonomy is a resource, which can not only supplement work resources, but also buffer work requirements. The increase in job autonomy has given employees the power to autonomously control work arrangements and schedules, which has strengthened employees' internal motivations and has had a positive impact, including work happiness and the improvement of work performance. Therefore, the marginal benefits of happiness and productivity, as shown by the solid line in Figure 1(a).

Regarding the loss path, the self depletion theory (Baumeister et al., 1998) holds that any activities will consume resources, and when resources are consumed too much, it will have a negative impact. Making work decisions independently, making work arrangements, and controlling the work process are all resource-consuming activities. When job autonomy is increased excessive, decision-making tasks consume a lot of resources, so that when processing work tasks, the remaining resources are limited. At this time, work efficiency will be reduced, and individuals will feel work pressure, so subjective well-being will also decline. That is the marginal loss increases. Autonomous control of work means that the outcome of the work depends on the individual. When job autonomy increases excessively, employees will face excessive work pressure and work responsibilities, coupled with insufficient resources, leading to a decrease in work efficiency and a decrease in subjective well-being. Therefore, with the increase of job autonomy, the loss in the early stage is relatively small. Once the increase of job autonomy exceeds the employee's processing capacity, the rate of this loss will rise rapidly, resulting in a faster growth rate of marginal loss in the later period, which is close rising straight, as shown by the dashed line in Figure $1(\mathrm{a})$.

Based on the path of gain and loss, it can be seen that in the first half of the increase in job autonomy, employees have more room to make work decisions and tasks, which increases their subjective happiness and work efficiency. Although there will be losses, the losses are small, the growth rate is slow, and the 


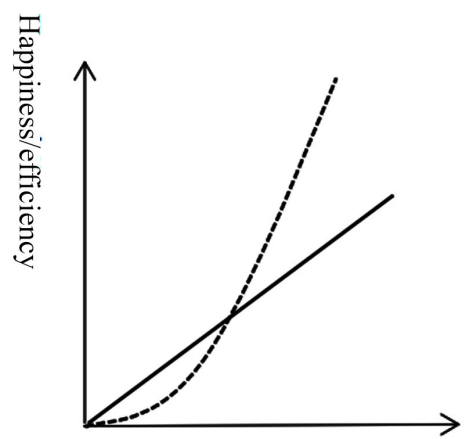

(a)

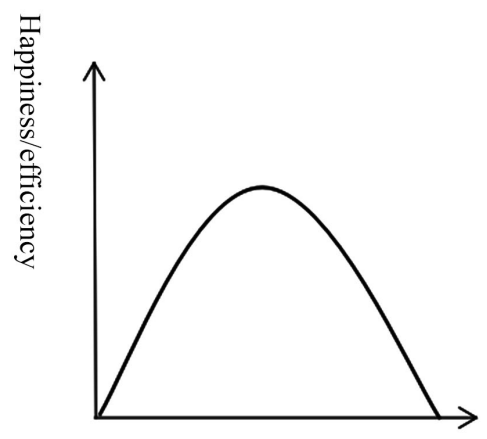

(b) job autonomy

Figure 1. The additive benefit and cost of job autonomy.

benefits are greater than the losses, showing a positive impact. However, with the excessive increase of autonomy in later work, the loss will become larger and larger, and the rate of loss will increase. When the marginal loss increases to the same amount as the marginal benefit, the subjective well-being and work efficiency brought by job autonomy reach the highest value, that is, the critical point of the "too-much-of-a-good-thing" effect, see Figure 1(b). Once the increase in job autonomy exceeds the threshold, it will lead to an increase in job responsibility and pressure, a shortage of remaining work resources, and a marginal loss growth rate that is faster than marginal income. It will enter the second half of the inverted $U$ shape, showing a negative impact.

\subsection{Interactive Motivation and Opportunity}

The second type of explanation mechanism focuses on the product of two potential relationships in the process of independent variables. At this time, the outcome variable is usually some form of performance or some behavior. The reason why "too-much-of-a-good-thing" is because as the level of the antecedent variable increases, the two types of factors change in opposite directions, constituting an increase and decrease interaction effect. Specifically, the promotion of outcome variables requires three factors: ability, motivation, and opportunity. Any two have an interactive effect on improving performance or behavior (Blumberg \& Pringle, 1982). Among them, motivation reflects the individual's subjective willingness to show a specific behavior, ability reflects the corresponding psychological and cognitive ability, and opportunity reflects the corresponding environmental factors. It can be seen that ability and opportunity together constitute various types of support conditions that are independent of will and enable individuals to show specific performances and behaviors. In the study of organizational behavior, the increase of independent variables usually leads to inconsistent changes in subjective will and support conditions, and motivation and ability (or opportunity) have thus shown a tendency to fade away. When the independent variable is lower or higher, the level of the two types of factors is higher and lower, the interaction effects are weaker, and the critical point is reached when the independent variable level is moderate. 
This mechanism can explain the "too-much-of-a-good-thing" effect of job autonomy on work deviation behaviors (counterproductive and unethical behavior) (see Figure 2). When working autonomy has a "too-much-of-a -good-thing" effect on the positive dependent variable, it presents an inverted $\mathrm{U}$-shaped curve. When it has a negative effect on the negative dependent variable, a U-shaped curve or a J-shaped curve appears, as shown in Figure 2(c). In the first half of the curve, an increase autonomy will control or reduce work deviation behavior. When job autonomy increases to a moderate level, job deviation behavior reaches a minimum. Subsequently, job autonomy continued to increase, and job deviation behavior increased. This article will explain how job autonomy can affect job deviation behaviors by the interaction between opportunity and motivation.

The increase in job autonomy has provided employees with a space to make autonomous decisions at work, and employees can make work plans and work behaviors in accordance with their needs and preferences. Increased job autonomy leaves room for individual behavioral performance at work, which actually creates opportunities for deviating behaviors in the workplace (Vardi \& Weitz, 2004). With free and flexible working hours, employees are prone to late arrival, early departure, and negative work delays. In addition, it reduced external monitoring, and deception, theft, and unethical behavior in the workplace have become available. Therefore, as job autonomy increases, so does the chance of misleading work behavior, see Figure 2(a).

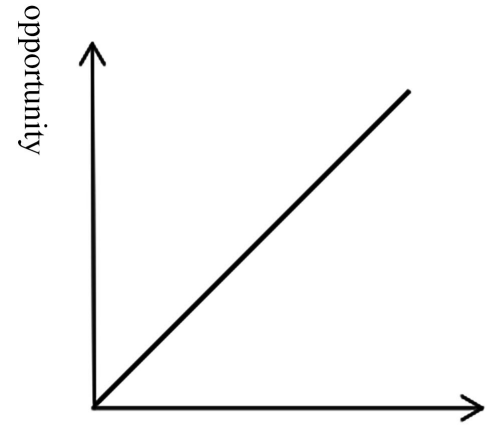

(a) job autonomy

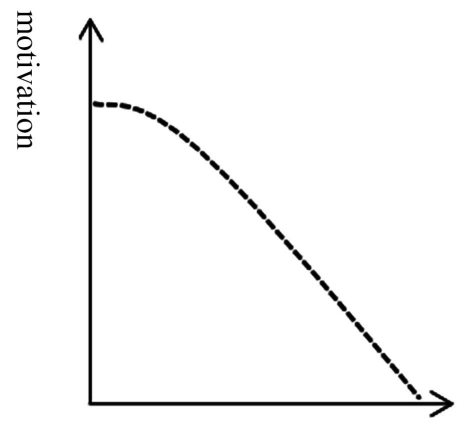

(b) job autonomy

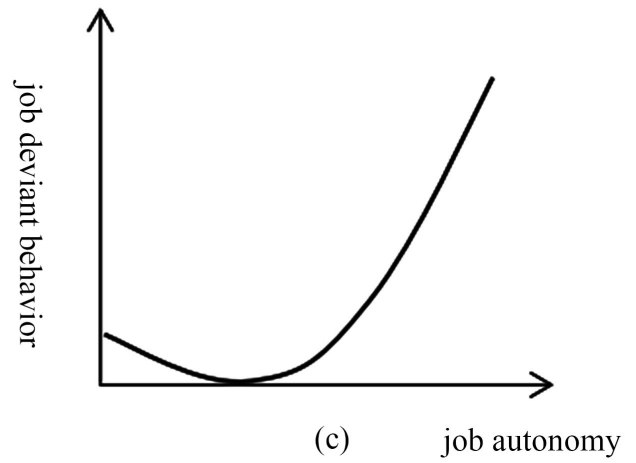

Figure 2. The additive benefit and cost of job autonomy. 
Increased job autonomy will also bring about a dynamic decline in employees' motivation to comply with regulations. According to the self-determination theory, when an individual gains autonomy at work, he will experience free will, which may induce the individual to feel free from rules. With less increase in job autonomy, motivation to follow the rules is at a high level. At this time, the expansion of the external free space may even enhance the employee's initiative and good behavior motivation. From the perspective of social exchange, this may be the feedback on increasing the organization's job autonomy. But when there is excessive increase in job autonomy, the work environment becomes free and relaxed, then employees' motivation to comply with the norms begins to decline, see Figure 2(b).

Then, the interaction of opportunity and motivation leads to the appearance of the J-curve. In the first half of the curve, the appropriate increase in job autonomy has given employees more freedom, but it has not reached the level of lack of external monitoring. Employees are still motivated to adhere to the rules of the organization, and in this situation, job deviations are less common. With the increase of job autonomy, the working environment becomes more flexible, and the monitoring is also decreasing. The motivation of employees to comply with the rules has begun to decline, and the self-interest deviation behavior motivation has gradually increased. Opportunity and motivation are combined to appear as work deviation behavior, then this behavior will appear more and more frequently with the increase of job autonomy, that is in the second half of the curve, the work deviation behavior gradually increases.

\section{Future Research Prospects}

It is not difficult to see that, in both theoretical analysis and empirical research, the negative impact of excessive autonomy on work is an important and new research area, which can be enriched and developed in many aspects in the future.

First, verifying the "too-much-of-a -good-thing" effect of job autonomy and exploring the position of critical points in different situations. At present, except for Warr (1994) and other empirical methods to prove the curve relationship between job autonomy and happiness, the inverted $U$ curve of job autonomy and other consequence has not been studied using empirical methods. Future research can focus on verifying the inverted U-curve relationship of job autonomy. Regarding the measurement method, Vergauwe, Wille, Hofmans, Kaise and Fruyt (2017) developed a new measurement method-TLTM scoring method for the "too little/too much" research area. TLTM scores are between -4 (too few), 0 (suitable), and 4 (too much). Compared with Likert scoring, the advantage is that the curve relationship between variables can be measured, and the "too-much-of-a-good-thing" effect can be measured in this way. On the other hand, for different outcome variables, the critical point of the work-in-progress effect may also be different. Future research can be enriched and developed from these aspects, and further answer questions such as which variables affect the job autonomy, how they affect them, and under what circumstances. 
Second, explore the characteristics and influence of excessive job autonomy in the Internet age. With the rapid development of the Internet, network office is also becoming more and more popular, such as email, fax, and communication software within the organization are commonly used tools. The change in office style is accompanied by an increase in job autonomy, and work arrangements, time, and location are also extremely flexible. Under such office conditions, excessive job autonomy has new characteristics and influences. On the one hand, excessive autonomy may be accompanied by a decline in self-control. Multi-task parallelism and switching, online information interruption, etc. are all phenomena that occur under the conditions of the Internet office. Employees often have less work focus due to greater flexibility. On the other hand, excessive autonomy requires employees to arrange work themselves. This is not only a work resource, but also a consumption. Because in today's work environment, not only are employees likely to make their own decisions; instead, they are forced to do so. They are increasingly able to independently plan and organize their own work schedules and decide how to handle work tasks. In this case, job autonomy is a necessary condition that requires extra effort and hinders task completion. It is necessary to explore the new features and influences of job autonomy in the Internet work environment, and it is worthy of attention in future research.

Third, pay attention to the job autonomy paradox in the Internet work environment. Research on knowledge workers has revealed that the tension between autonomy and control can lead to the so-called "autonomy paradox". Specifically, autonomy workers use the Internet to limit their autonomy when, where, and how to work, but believe that such restrictions will increase their ability and freedom as professional workers. The use of Internet tools to rely on autonomy to restrict job autonomy but perceives restrictive activity as a contradictory result that increases autonomy is called the autonomy paradox (Mazmanian, Orlikowski, \& Yates, 2013). Mazmanian et al. (2013) found that knowledge professionals using email devices to manage communications are developing a specification for continuous connectivity and accessibility, which has produced many conflicting results. The use of email provides these professionals with job autonomy, flexibility, and control of interactions in the short term, but at the same time enhances collective expectations of their usability. The continued use of mobile email devices has formed an escalating, collective, and dynamic impetus that has weakened the high degree of autonomy that professionals value. With the freedom to use the device at any time, any place, professionals will eventually use it anywhere, increasing their participation and reducing their ability to leave the job. In the Internet office environment, employees are facing more flexible choices. As scholars go deeper into the black box behind job autonomy, it will provide better management inspiration for the organization.

\section{Conclusion}

This article first briefly introduces the concept of job autonomy, and then focuses on explaining the "too-much-of-a-good-thing" effect of the job autonomy, 
and explains the mechanism with "additive benefit and cost" and "interactive motivation and opportunity". Finally, future research directions on the topic of job autonomy are proposed.

This article has theoretical implications and practical significance. In theory, for the first time, this article puts forward the "too-much-of-a-good-thing" effect of the job autonomy. At present, there are a lot of studies to explore the positive effects of job autonomy, and the research field is relatively mature. However, the negative effects of job autonomy have only recently been explored, and there is very little related research. The increase in job autonomy is likely to bring negative effects to employees or organizations in some aspects, but these negative effects are often easy to ignore and not easily detectable, so it is necessary to pay attention to the dark side of job autonomy valuable and meaningful.

In practice, blindly increasing job autonomy is not always good, and may have too much effect. With the change of the times and the change of the organization, the working characteristics are becoming more and more diverse, and the working environment is also very flexible. In such a dynamic environment, it is risky to increase job autonomy without depending on the specific situation. Therefore, organizations and supervisors should provide employees with a proper amount of job autonomy based on job characteristics and specific circumstances. For example, for those jobs that are more procedural programmed or operational tasks that are prone to boredom, you don't have to give too much autonomy. When you give more autonomy, you will leave space and opportunities to make deviations. For those creative work or market-oriented work, appropriate amount of job autonomy should be given, because employees engaged in this type of work need more flexibility in order to give full play to individual initiative to complete work tasks. Under the condition of autonomy, it will be subject to some constraints, and it is not easy to produce the best work performance.

\section{Conflicts of Interest}

The authors declare no conflicts of interest regarding the publication of this paper.

\section{References}

Bakker, A. B., \& Demerouti, E. (2007). The Job Demands-Resources Model: State of the Art. Journal of Managerial Psychology, 22, 309-328. https://doi.org/10.1108/02683940710733115

Baltes, B. B., Bauer, C. C., Bajdo, L. M., \& Parker, C. P. (2002). The Use of Multitrait-Multimethod Data for Detecting Nonlinear Relationships: The Case of Psychological Climate and Job Satisfaction. Journal of Business \& Psychology, 17, 3-17. https://doi.org/10.1023/A:1016231816394

Baltes, B. B., Briggs, T. E., Huff, J. W., Wright, J. A., \& Neuman, G. A. (1999). Flexible and Compressed Workweek Schedules: A Meta-Analysis of Their Effects on Work-Related Criteria. Journal of Applied Psychology, 84, 496-513.

https://doi.org/10.1037/0021-9010.84.4.496 
Baumeister, R. F., Bratslavsky, E., Muraven, M., \& Tice, D. M. (1998). Ego Depletion: Is the Active Self a Limited Resource? Journal of Personality and Social Psychology, 74, 1252-1265. https://doi.org/10.1037/0022-3514.74.5.1252

Blumberg, M., \& Pringle, C. D. (1982). The Missing Opportunity in Organizational Research: Some Implications for a Theory of Work Performance. Academy of Management Review, 7, 560-569. https://doi.org/10.5465/amr.1982.4285240

Breaugh, J. A. (1985). The Measurement of Job Autonomy. Human Relations, 38, 551-570. https://doi.org/10.1177/001872678503800604

Brink, A. G., Emerson, D. J., \& Yang, L. (2016). Job Autonomy and Counterproductive Behaviors in Chinese Accountants: The Role of Job-Related Attitudes. Journal of International Accounting Research, 15, 115-131. https://doi.org/10.2308/jiar-51194

Crawford, E. R., \& Lepine, J. A. (2013). A Configural Theory of Team Processes: Accounting for the Structure of Taskwork and Teamwork. Academy of Management Review, 38, 32-48. https://doi.org/10.5465/amr.2011.0206

Gino, F., \& Wiltermuth, S. S. (2014). Evil Genius? How Dishonesty Can Lead to Greater Creativity. Psychological Science, 25, 973. https://doi.org/10.1177/0956797614520714

Hackman, J. R., \& Oldham, G. R. (1976). Motivation through the Design of Work: Test of a Theory. Organizational Behavior \& Human Performance, 16, 250-279. https://doi.org/10.1016/0030-5073(76)90016-7

Lu, J. G., Brockner, J., Vardi, Y., \& Weitz, E. (2017). A Dark Side of Experiencing Job Autonomy: Unethical Behavior. Journal of Experimental Social Psychology, 73, 222-234. https://doi.org/10.1016/j.jesp.2017.05.007

Kelliher, C., \& Anderson, D. (2010). Doing More with Less? Flexible Working Practices and the Intensification of Work. Human Relations, 63, 83-106. https://doi.org/10.1177/0018726709349199

Kimmsw, H., \& Stoner, M. (2008). Burnout and Turnover Intention among Social Workers: Effects of Role Stress, Job Autonomy and Social Support. Administration in Social Work, 32, 5-25. https://doi.org/10.1080/03643100801922357

Kubicek, B., Paškvan, M., \& Bunner, J. (2017). The Bright and Dark Sides of Job Autonomy. In Job Demands in a Changing World of Work: Impact on Workers' Health and Performance and Implications for Research and Practice (pp. 45-63). Berlin: Springer International Publishing. https://doi.org/10.1007/978-3-319-54678-0_4

Malinowska, D., Tokarz, A., \& Wardzichowska, A. (2018). Job Autonomy in Relation to Work Engagement and Workaholism: Mediation of Autonomous and Controlled Work Motivation. International Journal of Occupational Medicine and Environmental Health, 31, 445-458. https://doi.org/10.13075/ijomeh.1896.01197

Mazmanian, M., Orlikowski, W. J., \& Yates, J. A. (2013). The Autonomy Paradox: The Implications of Mobile Email Devices for Knowledge Professionals. Organization Science, 24, 1337-1357. https://doi.org/10.1287/orsc.1120.0806

Morgeson, F. P., \& Humphrey, S. E. (2006). The Work Design Questionnaire (WDQ): Developing and Validating a Comprehensive Measure for Assessing Job Design and the Nature of Work. Journal of Applied Psychology, 91, 1321-1339.

https://doi.org/10.1037/0021-9010.91.6.1321

Park, R., \& Jang, S. J. (2015). Mediating Role of Perceived Supervisor Support in the Relationship between Job Autonomy and Mental Health: Moderating Role of Value-Means Fit. The International Journal of Human Resource Management, 28, 703-723. https://doi.org/10.1080/09585192.2015.1109536

Robinson, S. L., \& Bennett, R. J. (1995). A Typology of Deviant Workplace Behaviors: A Multidimensional Scaling Study. Academy of Management Journal, 38, 555-572. 
https://doi.org/10.2307/256693

Searcy, P. D. (2012). Job Autonomy as a Predictor of Mental Well-Being: The Moderating Role of Quality-Competitive Environment. Journal of Business and Psychology, 27, 305-316. https://doi.org/10.1007/s10869-011-9244-3

Sia, S. K., \& Appu, A. V. (2015). Job Autonomy and Workplace Creativity: Moderating Role of Task Complexity. Global Business Review, 16, 772-784. https://doi.org/10.1177/0972150915591435

Taris, T. W. (2006). Bricks without Clay: On Urban Myths in Occupational Health Psychology. Work \& Stress, 20, 99-104. https://doi.org/10.1080/02678370600893410

Vardi, Y., \& Weitz, E. (2004). Misbehavior in Organizations: Theory, Research, and Management. Mahwah, NJ: Erlbaum. https://doi.org/10.4324/9781410609052

Vergauwe, J., Wille, B., Hofmans, J., Kaiser, R. B., \& Fruyt, F. D. (2017). The Too Little/Too Much Scale: A New Rating Format for Detecting Curvilinear Effects. Organizational Research Methods, 20, 518-544. https://doi.org/10.1177/1094428117706534

Warr, P. B. (1994). A Conceptual Framework for the Study of Work and Mental Health. Work \& Stress: An International Journal of Work, Health \& Organisations, 8, 84-97. https://doi.org/10.1080/02678379408259982

Xing, L., Sun, J. M., Yin, K., \& Wang, Z. (2018). The Too-Much-of-a-Good-Thing Effect and Its Mechanisms. Advances in Psychological Science, 26, 719-730.

https://doi.org/10.3724/SP.J.1042.2018.00719

Yang, T. S., Pandey, A., \& Liao, Y. (2017). A Path from Job Autonomy to Organizational Citizenship Behavior: The Role of Perceived Organizational Politics as Mediator. Journal of Business and Behavioral Sciences, 29, 44-56. 